\title{
Scrutiny is the best way of delivering fair treatment
}

Nina Champion and Hannah Pittaway, Criminal Justice Alliance. 
When the criminal justice system treats someone poorly, inhumanely or in a discriminatory way, it can cause long-lasting harm, pushing them deeper into the powerful current of crime and damaging their potential for a healthy, productive life. To prevent this, it is essential that outcomes for people impacted by the criminal justice system are monitored and that criminal justice agencies are scrutinised and held to account.

\section{Scrutiny and fairness}

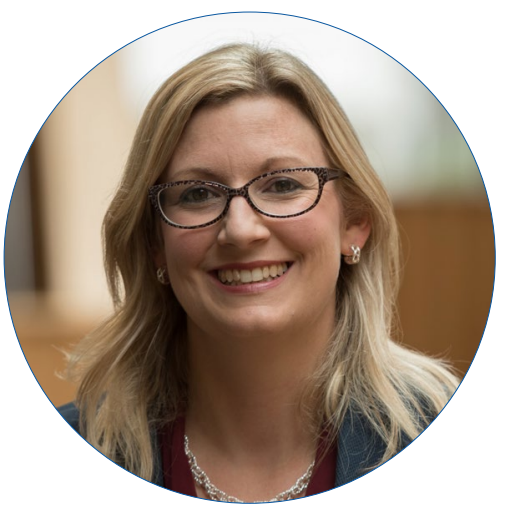

Nina Champion

Director

Criminal Justice Alliance

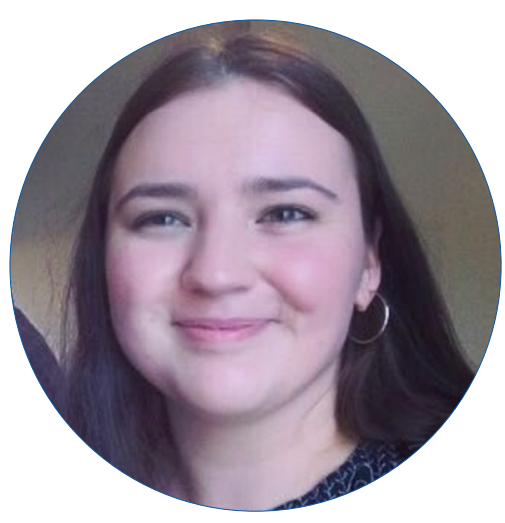

Hannah Pittaway

Senior Policy Officer

Criminal Justice Alliance 
There are three broad categories of scrutiny mechanism in the CJS:

1. Community monitoring: This is where volunteers from the public scrutinise aspects of the CJS.

2. Her Majesty's Inspectorates: Independent bodies inspect constabularies, the Crown Prosecution Service, prisons and probation.

3. Investigative bodies: There are also investigative bodies such as the Prisons and Probation Ombudsman (PPO), which investigates complaints and deaths to understand what happened, correct injustices and identify learning. In addition, the Independent Office for Police Complaints (IOPC) investigates the most serious and sensitive incidents and allegations involving the police as well as how the police handle complaints.

In our work over the past three years, we have focused on investigating the effectiveness of community scrutiny mechanisms including: Community Scrutiny Panels (which review the use of police stop and search powers), Independent Custody Visitors (who monitor the welfare and treatment of people in police custody) and Independent Monitoring Boards (which monitor outcomes for people in prison). ${ }^{2}$

\section{What does effective community scrutiny look like?}

Based on our work we have identified four broad principles for effective community scrutiny:

1. Independent and empowered: It should be led by the community, provide constructive challenge and have the ability to influence positive change.
2. Representative: It should reflect the demographics of the people impacted by the CJS in the service / setting which is being scrutinised.

3. Informed: It should have access to a wide range of data and records, as well as the training and skills, to analyse and identify any disparities in outcomes for people with protected characteristics.

4. Open and visible: It should promote its work widely to the community, publish summaries/reports of its work and be easily accessible to the local community and the people impacted by the service/setting it is scrutinising.

Since the publication of our Stop \& Scrutinise report (2019) $)^{3}$ which highlighted these principles, we have seen some evidence of them being adopted; for example, in the College of Policing's new guidance on community scrutiny of stop and search in 2020, and in the government's recent Commission on Race and Ethnic Disparities $(2021)^{4}$ which calls for the establishment of 'Safeguarding Trust' groups to scrutinise policing.

However, we have found that community scrutiny bodies often find it hard to adhere fully to these four principles, impacting their effectiveness. For example, community scrutiny bodies tend to reflect their local community demographics, rather than the demographics of the people directly impacted by the service being monitored. Although there are some examples of good practice in increasing the diversity of scrutiny volunteers, such as through outreach with universities, religious organisations and community groups led by and for Black, Asian and minority ethnic people, there remains a worrying lack of racial diversity across the community scrutiny bodies we have looked at.

\footnotetext{
${ }^{2}$ The full reports relating to our work with ICVA and IMB will be published in the next couple of months.

3 https://www.criminaljusticealliance.org/cja-resources/stop-scrutinise-how-to-improve-community-scrutiny-of-stop-and-search/

4 Crime and policing - GOV.UK (wWw.gov.uk)
} 
There is also a lack of access to detailed data and skills enabling them to understand if disparities exist. For example, in prisons, IMB members need access to granular level demographic and statistical data on issues such as use of force, segregation, access to healthcare and Release on Temporary Licence (ROTL) to understand if there is any indirect discrimination. IMBs have a right to access such prison data to support their monitoring. However, the availability of this data varies across prisons. In police custody, visitors who have access to custody records, as well as being able to speak to detainees, are better able to monitor equality issues. But not all schemes have access to these records. Meanwhile, stop and search statistics can be complex to understand and a lack of training for community scrutiny panel members prevents them from effectively analysing data.

There is also a lack of understanding of the Public Sector Equality Duty (a legal obligation for public bodies under the Equality Act 2010), the historic context of race in the CJS, as well as on topics such as anti-racism and cultural competence. And where scrutiny bodies have highlighted concerns or made recommendations about equality issues, there is often frustration at the lack of progress in influencing change. We found some examples of success, such as the police proactively offering women menstrual products in police custody and prisons organising cultural events or making available more culturally appropriate canteen products. But there is still much more for criminal justice bodies to do at both operational and systemic levels to not only remove direct and indirect discrimination, but to proactively foster good relations and advance equality of opportunity, as set out in the Public Sector Equality Duty.

Despite these challenges, community oversight remains an important mechanism for holding public bodies to account, promoting transparency, scrutinising decision-making and creating a fairer and more effective CJS. By focusing on the four principles, these bodies could increase their effectiveness and improve the lives of people in touch with the CJS.

\section{Community scrutiny for probation?}

The probation service is one part of the CJS that lacks an independent community scrutiny mechanism. This has not always been the case. In 2014, the government changed the management structure of the service. Before the 'Transforming Rehabilitation' reforms came into effect, there were Local Probation Boards which provided a community scrutiny function. However, when Community Rehabilitation Companies (CRCs) were established, this community scrutiny function was removed.

Given the unification of the probation service, combined with the findings of the recent thematic report from Her Majesty's Inspectorate of Probation on 'Race Equality in Probation'6, it is now time to consider whether a community scrutiny mechanism for probation should be reintroduced, and if so, what it should look like to be effective.

\footnotetext{
${ }^{5}$ Public sector equality duty - GOV.UK (www.gov.uk)

6 https://www.justiceinspectorates.gov.uk/hmiprobation/inspections/race-equality-in-probation/
} 
In the Lammy Review, with regard to probation, it was suggested that equalities assessments should provide detailed breakdowns of services for different ethnic and religious groups and data 'should be published in a format that allows contract managers and those outside - from civil society campaigners to parliamentary select committees, or the National Audit Office (NAO) to scrutinise [probation's] performance."7

While HMI Probation inspects each probation region annually, we would argue that - as with other aspects of the CJS - a permanent onthe-ground presence could provide real-time intelligence gathering. This would provide a layer of scrutiny and accountability that is currently missing. It would also engage the public in better understanding the work of probation.

It was noted in the PPO's most recent annual report that 282 complaints were received about probation services, which only represents 7 percent of the total complaints received by the PPO. The report states that the PPO has begun thinking about how its complaints mechanism is viewed by people on probation and why it receives so few complaints. A community scrutiny mechanism for probation could shed light on this issue. It could engage people on probation through phone calls, attending probation waiting rooms or through site visits to approved probation hostels and settings involved with community sentences. If efforts were made to ensure the membership was diverse and there was sufficient training and data on equalities issues, it could also help tackle the issues identified by $\mathrm{HMI}$ Probation in its recent report on race and improve outcomes for people on probation with protected characteristics.

\section{Next steps}

We'll shortly be publishing the final reports of our work on community scrutiny and equality issues in prison custody in partnership with the Independent Monitoring Boards and police custody in partnership with the Independent Custody Visitors Association. We look forward to using these findings and working with our members and others to help co-design a community scrutiny mechanism for the probation service, drawing on examples of community scrutiny that some probation areas may have already implemented.

If you are interested in this work, we would love to hear from you. Please email:

nina.champion@criminaljusticealliance.org.uk

\footnotetext{
7 Public bodies are meant to give 'due regard' to ensuring that their policies, practices and decision-making processes do not directly or indirectly discriminate against any groups with protected characteristics, promote equality and foster good relations. Carrying out Equality Impact Assessments (EIAs) are one-way public bodies can show they have done this.
} 